\title{
The Transition From Undernutrition to Overnutrition Under Adverse Environments and Poverty: The Risk for Chronic Diseases
}

\author{
Paola Caroline L. Leocádio ${ }^{1,2}$, Synara C. Lopes ${ }^{3}$, Ronaldo P. Dias ${ }^{3}$, \\ Jacqueline I. Alvarez-Leite ${ }^{1}$, Richard L. Guerrant ${ }^{4}$, João O. Malva ${ }^{5,6}$ and Reinaldo B. Oriá ${ }^{3 *}$ \\ ${ }^{1}$ Laboratory of Atherosclerosis and Nutritional Biochemistry, Department of Biochemistry and Immunology, Federal University \\ of Minas Gerais, Belo Horizonte, Brazil, ${ }^{2}$ Department of Nutrition, Nursing School, Federal University of Minas Gerais, Belo \\ Horizonte, Brazil, ${ }^{3}$ Laboratory of Tissue Healing, Ontogeny, and Nutrition, Faculty of Medicine, Federal University of Ceará, \\ Fortaleza, Brazil, ${ }^{4}$ Center for Global Health, University of Virginia, Charlottesville, VA, United States, ${ }^{5}$ Coimbra Institute for \\ Clinical and Biomedical Research (iCBR), Faculty of Medicine, University of Coimbra, Coimbra, Portugal, ${ }^{6}$ Center for \\ Innovative Biomedicine and Biotechnology (CIBB), University of Coimbra, Coimbra, Portugal
}

Keywords: malnutrition, obesity, intestinal microbiota, diet, COVID-19, dysbiosis, poverty

OPEN ACCESS

Edited by:

Vittorio Calabrese,

University of Catania, Italy

Reviewed by:

Erika Elizabeth Rodriguez-Torres, Autonomous University of the State of

Hidalgo, Mexico

${ }^{*}$ Correspondence: Reinaldo B. Oriá

oria@ufc.br

Specialty section:

This article was submitted to Neuroenergetics, Nutrition and Brain Health,

a section of the journal

Frontiers in Nutrition

Received: 04 March 2021 Accepted: 26 March 2021

Published: 23 April 2021

Citation:

Leocádio PCL, Lopes SC, Dias RP Alvarez-Leite Jl, Guerrant RL, Malva JO and Oriá RB (2021) The

Transition From Undernutrition to

Overnutrition Under Adverse

Environments and Poverty: The Risk

for Chronic Diseases.

Front. Nutr. 8:676044.

doi: 10.3389/fnut.2021.676044
Nutritional transition is an important public health issue in developing countries, where switch from undernutrition to overnutrition/obesity is rapidly occurring, often within two or three generations. Such transition is related to changes in lifestyle, with people having more access to western high-caloric diets. In developing countries, settings of poverty, poor sanitation and hygiene are still common, where children are exposed to numerous enteric pathogens, pollutants, and other biohazards. Populations living under such adverse environments and facing the nutritional transition may have increased risks for chronic illnesses in later life, including diabetes, cardiovascular, and neurodegenerative diseases. This opinion paper summarizes novel findings and recent literature addressing the nutrition transition under adverse environments, including the gut microbiota-brain axis dysfunction and their lasting effects with deleterious consequences for later development.

\section{DIETARY CHANGES IN DEVELOPING COUNTRIES}

According to the World Health Organization (WHO), approximately 462 million adults are underweight, 1.9 billion are overweight or obese, and 2 billion are micronutrient deficient (1). In addition, 38 million children below 5 years of age were overweight or obese in 2019 and more than 340 million children and adolescents (5 to 19 years) were overweight or obese in 2016 (2). Obesity associated with micronutrient deficiency has great repercussions in childhood and deserves special attention in middle and low income countries (3), which may be even more aggravated by poverty and unbalanced diets.

In developing countries, lifestyle changes amidst the disarray of urbanization, increasing poverty (with proliferating shantytowns, poor sanitation, and hygiene), crowding, and altered dietary habits. Continuous exposure to harmful pollutants (mercury, lead, arsenic, asbestos etc.) and environmental pathogens may accumulate and lead to a detrimental exposome throughout life with long-term health consequences (4).

In developing countries with emerging economies, a double burden of malnutrition (DBM) often occurs even in impoverished areas. The DBM is defined by WHO as "the coexistence of undernutrition along with overweight, obesity or diet-related non-communicable diseases (NCD), within individuals, households and populations, and across the life-course" and may be 
aggravated by poor environmental circumstances and genetic predispositions (1). Although a large proportion of deaths among children under five are attributed to malnutrition, overweight and obesity in this age group and older are on the rise (5). The increased risk of NCD related with the nutritional transition in developing countries is a public health concern, due to the potential economic impact and oversaturation of the health system infrastructure (6).

Furthermore, when nutritional deprivation or infection occurs early in life, such as in the prenatal phase and/or up to 3 years of age, the individual undergoes metabolic changes that can lead to greater susceptibility to developing obesity as an adult (7). DBM can cause long-term effects, especially when their components develop early, and each of them can increase the chances of the other occurring (8).

The transition to hypercaloric diets is a global health concern. Hypercaloric intake is characterized by high-carbohydrate and fat consumption, both leading to obesity. Studies have shown that maternal obesity during pregnancy can lead to overweight and other metabolic effects in the offspring through epigenetic mechanisms, such as DNA methylation (9). The coexistence of these opposing nutritional patterns reflects, in part, social and economic inequalities. Other factors such as the increased life expectancy also contribute, as elderly populations are more vulnerable to malnutrition given their psychological, social and health-related risks and chronic diseases (10).

\section{IMPACT OF NUTRITIONAL TRANSITION IN DEVELOPING COUNTRIES}

Several studies point to the effects of fetal programming and maternal and environmental factors during early life on the development of diseases in adulthood (11-16). Maternal nutrition even before pregnancy can affect the development of the fetus with later risk for cardiovascular/metabolic diseases (12). Early undernutrition followed by later overweight increases the risk of NCD, imposing a high metabolic load on a reduced or altered capacity for homeostasis. In women, early childhood undernutrition increases the risk of complications in childbirth later in life (13). In countries with poor sanitary conditions, the occurrence of the APOE4, a recognized gene associated with increased risk for acquiring Alzheimer's disease, may favor maternal fertility and promote protection against childhood diarrhea, while possibly increasing the risk of NCD with aging (14). In animal models, maternal obesity affects leptin mRNA expression and its peak in offspring (15). Hyperleptinemia leads to leptin resistance in neonates, favoring hyperphagia and can permanently affect the regulation of appetite (16). These trajectories throughout life are shaped both by driving factors of society-that is, rapid changes in diets, dietary norms and patterns of physical activity-and by broader ecological factors, such as pathogen exposure (8).

In the example of Brazil, the most recent National Health Survey (17) pointed out that $60.3 \%$ of the population over 18 years old is overweight, while underweight reaches $1.6 \%$ of the inhabitants over 25 years old. A systematic review (18) pointed out that the prevalence of underweight was approximately $10 \%$ in children from different regions of the country, reaching $21 \%$ due to social disparities. The prevalence of overweight was also approximately $10 \%$, with a reduction to $6 \%$ in populations with social inequality.

The increase in the body mass index (BMI) in the population has grown significantly not only in Brazil but in other lowand middle-income countries around the globe, justifying the increase in the incidences of NCD. Yiengprugsawan et al. (19) studied the populations of Brazil and Thailand because both went through similar economic transitions with the hypothesis of the existence of a relationship between BMI and socioeconomic status. In this study, socioeconomic status was directly related to the increase in overweight and obesity in males. In women, an inverse pattern was observed for both cohorts throughout the study period (19).

A more recent survey conducted in Greece after the economic crisis, showed that there are still inequalities in the nutritional level. The DBM is present in populations dependent on the government's food assistance program. The food of the neediest people is unfortunately characterized by a high consumption of processed foods containing refined sugar and a scarce intake of fruits and vegetables. Greece is also undergoing a nutritional transition phase initiated by the economic crisis that occurred 10 years ago and that today still affects the poorest population (20).

\section{DIETARY IMBALANCE AND INFLAMMATION: FROM THE GUT TO THE BRAIN}

The dynamic gut microbial ecosystem is directly influenced by the diet and by its bidirectional interaction with the health of the host. In the context of DBM, literature points out that changes in the microbiota can be profoundly influenced by both undernutrition and obesity (5). Long-lasting effects of undernutrition in early life can be attributed to interconnected biological pathways, involving imbalance of the gut microbiome, inflammation, metabolic dysregulation, and impaired insulin signaling (8).

The immaturity of the microbiota, the increased burden of enteric pathogens and the dysfunction of the intestinal barrier are associated with systemic inflammation in early life, that may have lasting disabling effects (21). Contaminated environments, early childhood diarrhea and enteric pathogens have been associated with intestinal dysbiosis, increased risk of developing obesity (22) and neurodegenerative diseases $(23,24)$. Studies have shown the impact of diet and obesity on gut microbiota. High-fat diets may promote dysbiosis (25) and the gut microbiota was stated as a further contributing factor to pathophysiology of obesity by influencing insulin resistance and systemic inflammation (26). Among obese adults with similar BMI, those with greater dysbiosis have a higher risk of NCD (27). Some have suggested that changes in the microbiota promoted by SARS-CoV-2 infection associated with dietary changes may exacerbate present and future health risks (5). 
Moreover, the relationship between COVID-19 and nutrition is reciprocal. Both, obesity and micronutrient deficiencies increase the risk and aggravates the evolution of COVID19, which, in turn, due to its devastating effect, leads to undernutrition. Moreover, social distancing leads to physical inactivity, less frequent sun exposure (reducing stokes of vitamin D), increases stress and reduces medical visits for non-related COVID-19 symptoms (28).

Both undernutrition and obesity may induce low-grade systemic inflammation $(29,30)$. The adipose tissue secretes several inflammatory mediators and these molecules can exert metabolic, cardiovascular and hepatic effects, among others, favoring the development of NCD (31). In the elderly, the increase in systemic inflammation indicators is related to atherosclerosis, diabetes, neurodegenerative diseases, and carcinogenesis, however it is still not entirely clear why lowgrade chronic inflammation is associated with the development of chronic diseases (32).

It has been increasingly recognized that imbalanced diets may be per se an proinflammatory factor. The literature presents accumulating evidence that points to the connection between diet, inflammation and NCD (33). These data are essential to find out how obesity is outlined and impacts on the emerging metabolic disorders. The diet lipid content profile can modulate pro-inflammatory genes expression (34). Prolonged consumption of a high-fat diet promotes an increase in inflammatory mediators in the central nervous system and peripheral tissues including liver and adipose tissue (35). Interestingly, (44) observed greater lipid deposition in animals that consumed a diet rich in fat but found a higher concentration of inflammatory mediators in animals that received a diet rich in carbohydrates.

One of the recently studied molecules in non-alcoholic fatty liver disease associated with obesity, involving hyperlipidemia, hyperglycemia and insulin resistance is perilipin-2, a cytoplasmic protein that covers lipid droplets (36). Kern et al. (37) observed greater expression of the protein in obese humans, not associated with an increase in inflammatory mediators and insulin resistance. In animals fed a high-fat diet, the deletion of the perilipin-2 gene prevented obesity, inflammation of adipose tissue, insulin resistance and steatosis (38). Perilipin-2 also appears to play a role in intestinal dysbiosis promoted by a high-fat diet (39).

In summary, dietary changes observed in DBM can contribute to the development of NCD, calling attention for the utmost need to study and implement actions that can mitigate its effects.

\section{WHAT CAN BE DONE TO REDUCE THE IMPACT OF THE NUTRITIONAL TRANSITION ON THE DEVELOPMENT OF CHRONIC DISEASES?}

From observing the effects of the nutritional transition on health and quality of life, especially in countries facing DBM-in which the health system needs to cope with great demands for both addressing poor diet and sanitation in early life as well as the costly management of chronic diseases as adults age (40), interventions are needed to reduce these worrisome impacts.

Interventions, programs, and policies with the potential to simultaneously reduce DBM are called double-duty actions: improving maternal and child nutrition, encouraging breastfeeding, school feeding policies and programs and marketing regulations (41). A scoping review concludes that there are few studies evaluating the effect of these actions to reduce both undernutrition and overnutrition (42). Recent work criticizes double-duty actions, suggesting expansion of the groups contemplated, for example including women of reproductive age in the pre and post-pregnancy periods, expanding the focus of nutrition to general health. Still, some determinants associated with DBM are not considered, such as better access to potable water, which raises the question of the need to revisit and update the current intervention strategies (43).

\section{CONCLUSION}

The double burden posed by early childhood undernutrition with later life continued poor, high fat diets may have lasting consequences that need to be addressed by sanitary authorities. As the health access improves and life expectancy increases in developing countries, the compound effect of early-life DBM in aging populations even more raises the concern and thus requires more attention by health policies.

In times of COVID-19 pandemic, exacerbation of DBM is foreseen, with likely increased rates of undernutrition (due to micronutrient deficiency, diet imbalance, e.g., vitamin D deficiency) and obesity (food choices, lockdowns, and restrictions on mobility) worldwide, but in low and middle income countries such lifestyle changes, when compounded with adverse environments and poverty may have a profound impact for health and likely increasing the risk for acquiring/aggravating chronic diseases (43). This opinion paper calls for more awareness of this public health issue and the need for long-term cohort studies to follow-up and bring innovative strategies to ameliorate potentially lasting effects of the nutrition transition, especially under adverse environments.

\section{AUTHOR CONTRIBUTIONS}

All authors have equally contributed to the work and approved it for publication.

\section{FUNDING}

JOM was supported by FCT (Portuguese Foundation for Science and Technology) through the Strategic Project UIBD/04539/2020, UIDP/04539/2020 (CIBB), and POCI01-0145-FEDER-007440, CENTRO-01-0145-FEDER-0000012: Healthy Aging 2020. 


\section{ACKNOWLEDGMENTS}

The authors would like to thank the Brazilian National Council for Scientific and Technological Development [CNPq] especial visiting researcher $\left[\mathrm{N}^{\circ} 03 / 2014\right.$, \# 400538/2014-8]

\section{REFERENCES}

1. World Health Organization. The Double Burden of Malnutrition. Policy Brief. World Health Organization (2017). p. 10. Available online at: https://www. who.int/publications/i/item/WHO-NMH-NHD-17.3 (accessed February 8, 2021).

2. World Health Organization. Obesity and Overweight. Available online at: https://www.who.int/news-room/fact-sheets/detail/obesity-and-overweight (accessed February 8, 2021).

3. Jardim-Botelho A, Queiroz Gurgel R, Simeone Henriques G, Dos Santos CB, Afonso Jordão A, Nascimento Faro F, et al. Micronutrient deficiencies in normal and overweight infants in a low socio-economic population in north-east Brazil. Paediatr Int Child Health. (2016) 36:198-202. doi: 10.1179/2046905515Y.0000000035

4. Tshala-Katumbay D, Mwanza J-C, Rohlman DS, Maestre G, Oriá RB. A global perspective on the influence of environmental exposures on the nervous system. Nature. (2015) 527:S187-92. doi: 10.1038/nature16034

5. Littlejohn P, Finlay BB. When a pandemic and an epidemic collide: COVID19, gut microbiota, and the double burden of malnutrition. BMC Med. (2021) 19:1-8. doi: 10.1186/s12916-021-01910-z

6. Mbogori T, Kimmel K, Zhang M, Kandiah J, Wang Y. Nutrition transition and double burden of malnutrition in Africa: a case study of four selected countries with different social economic development. AIMS Public Heal. (2020) 7:425-39. doi: 10.3934/publichealth.2020035

7. Deboer MD, Lima AAM, Oría RB, Scharf RJ, Moore SR, Luna MA, et al. Early childhood growth failure and the developmental origins of adult disease: do enteric infections and malnutrition increase risk for the metabolic syndrome? Nutr Rev. (2012) 70:642-53. doi: 10.1111/j.1753-4887.2012.00543.x

8. Wells JC, Sawaya AL, Wibaek R, Mwangome M, Poullas MS, Yajnik CS, et al. The double burden of malnutrition: aetiological pathways and consequences for health. Lancet. (2020) 395:75-88. doi: 10.1016/S0140-6736(19)32472-9

9. Hjort L, Martino D, Grunnet LG, Naeem H, Maksimovic J, Olsson $\mathrm{AH}$, et al. Gestational diabetes and maternal obesity are associated with epigenome-wide methylation changes in children. JCI Insight. (2018) 3:114. doi: 10.1172 /jci.insight. 122572

10. Prince MJ, Wu F, Guo Y, Gutierrez Robledo LM, O’Donnell M, Sullivan R, et al. The burden of disease in older people and implications for health policy and practice. Lancet. (2015) 385:549-62. doi: 10.1016/S0140-6736(14)61347-7

11. Kronman H, Torres-Berrío A, Sidoli S, Issler O, Godino A, Ramakrishnan A, et al. Long-term behavioral and cell-type-specific molecular effects of early life stress are mediated by H3K79me2 dynamics in medium spiny neurons. Nat Neurosci. (2021). doi: 10.1038/s41593-021-00814-8. [Epub ahead of print].

12. Young MF, Ramakrishnan U. Maternal undernutrition before and during pregnancy and offspring health and development. Ann Nutr Metab. (2021) 76:1-13. doi: 10.1159/000510595

13. Victora CG, Adair L, Fall C, Hallal PC, Martorell R, Richter L, et al. Maternal and child undernutrition: consequences for adult health and human capital. Lancet. (2008) 371:340-57. doi: 10.1016/S0140-6736(07)61692-4

14. Oriá RB, de Almeida JZ, Moreira CN, Guerrant RL, Figueiredo JR. Apolipoprotein $\mathrm{E}$ effects on mammalian ovarian steroidogenesis and human fertility. Trends Endocrinol Metab. (2020) 31:87283. doi: $10.1016 /$ j.tem.2020.06.003

15. Kirk SL, Samuelsson AM, Argenton M, Dhonye H, Kalamatianos T, Poston $\mathrm{L}$, et al. Maternal obesity induced by diet in rats permanently influences central processes regulating food intake in offspring. PLoS ONE. (2009) 4:e5870. doi: 10.1371/journal.pone.0005870

16. Toste FP, de Moura EG, Lisboa PC, Fagundes AT, de Oliveira E, Passos MCF. Neonatal leptin treatment programmes leptin hypothalamic resistance and and the Coordination for the Improvement of Higher Education Personnel [CAPES] Procad [071/2013 \# 144494] and CAPES PrInt funding. RO was supported in part by the Bill and Melinda Gates Foundation grant \# OPP1137923. intermediary metabolic parameters in adult rat. Br J Nutr. (2006) 95:8307. doi: $10.1079 /$ BJN20061726

17. Instituto Brasileiro de Geografia e Estatística. Pesquisa Nacional de Saúde 2019. (2020). Available online at: https://www.ibge.gov.br/estatisticas/sociais/ saude/9160-pesquisa-nacional-de- saude.html?=\&t=downloads (accessed February 15, 2021).

18. Sousa CP da C, de Olinda RA, Pedraza DF. Prevalence of stunting and overweight/obesity among Brazilian children according to different epidemiological scenarios: systematic review and meta-analysis. São Paulo Med J. (2016) 134:251-62. doi: 10.1590/1516-3180.2015.0227121

19. Yiengprugsawan V, Horta BL, Motta JVS, Gigante D, Seubsman S-A, Sleigh A. Body size dynamics in young adults: 8-year follow up of cohorts in Brazil and Thailand. Nutr Diabetes. (2016) 6:e219. doi: 10.1038/nutd.2016.24

20. Chatzivagia E, Pepa A, Vlassopoulos A, Malisova O, Filippou K, Kapsokefalou M. Nutrition transition in the post-economic crisis of greece: assessing the nutritional gap of food-insecure individuals. A cross-sectional study. Nutrients. (2019) 11:2914. doi: 10.3390/nu11122914

21. Blanton LV, Barratt MJ, Charbonneau MR, Ahmed T, Gordon JI. Childhood undernutrition, the gut microbiota, and microbiota-directed therapeutics. Science. (2016) 352:1533. doi: 10.1126/science.aad9359

22. Guerrant RL, Deboer MD, Moore SR, Scharf RJ, Lima AAM. The impoverished gut - A triple burden of diarrhoea, stunting and chronic disease. Nat Rev Gastroenterol Hepatol. (2013) 10:220-9. doi: 10.1038/nrgastro.2012.239

23. Oriá RB, Murray-Kolb LE, Scharf RJ, Pendergast LL, Lang DR, Kolling GL, et al. Early-life enteric infections: Relation between chronic systemic inflammation and poor cognition in children. Nutr Rev. (2016) 74:37486. doi: $10.1093 /$ nutrit/nuw008

24. Oriá RB, Malva JO, Foley PL, Freitas RS, Bolick DT, Guerrant RL. Revisiting inbred mouse models to study the developing brain: the potential role of intestinal microbiota. Front Hum Neurosci. (2018) 12:15. doi: $10.3389 /$ fnhum. 2018.00358

25. Ussar S, Griffin NW, Bezy O, Fujisaka S, Vienberg S, Softic S, et al. Interactions between gut microbiota, host genetics and diet modulate the predisposition to obesity and metabolic syndrome. Cell Metab. (2015) 22:51630. doi: 10.1016/j.cmet.2015.07.007

26. Lazar V, Ditu LM, Pircalabioru GG, Picu A, Petcu L, Cucu N, et al. Gut microbiota, host organism, and diet trialogue in diabetes and obesity. Front Nutr. (2019) 6:21. doi: 10.3389/fnut.2019.00021

27. de la Cuesta-Zuluaga J, Corrales-Agudelo V, Carmona JA, Abad JM, Escobar JS. Body size phenotypes comprehensively assess cardiometabolic risk and refine the association between obesity and gut microbiota. Int J Obes. (2018) 42:424-32. doi: 10.1038/ijo.2017.281

28. Palmer K, Monaco A, Kivipelto M, Onder G, Maggi S, Michel J-P, et al. The potential long-term impact of the COVID-19 outbreak on patients with noncommunicable diseases in Europe: consequences for healthy ageing. Aging Clin Exp Res. (2020) 32:1189-94. doi: 10.1007/s40520-020-01601-4

29. Calder PC, Ahluwalia N, Brouns F, Buetler T, Clement K, Cunningham K, et al. Dietary factors and low-grade inflammation in relation to overweight and obesity. Br J Nutr. (2011) 106:S5-78. doi: 10.1017/S0007114511005460

30. Prendergast AJ, Rukobo S, Chasekwa B, Mutasa K, Ntozini R, Mbuya MNN, et al. Stunting is characterized by chronic inflammation in zimbabwean infants. PLoS ONE. (2014) 9:e86928. doi: 10.1371/journal.pone.0086928

31. Zatterale F, Longo M, Naderi J, Raciti GA, Desiderio A, Miele C, et al. Chronic adipose tissue inflammation linking obesity to insulin resistance and type 2 diabetes. Front Physiol. (2020) 10:1607. doi: 10.3389/fphys.2019.01607

32. Pawelec G, Goldeck D, Derhovanessian E. Inflammation, ageing and chronic disease. Curr Opin Immunol. (2014) 29:23-8. doi: 10.1016/j.coi.2014.03.007 
33. Duan Y, Zeng L, Zheng C, Song B, Li F, Kong X, et al. Inflammatory links between high fat diets and diseases. Front Immunol. (2018) 9:110. doi: 10.3389/fimmu.2018.02649

34. Corrêa TAF, Quintanilha BJ, Norde MM, Pinhel MA de S, Nonino CB, Rogero MM. Nutritional genomics, inflammation and obesity. Arch Endocrinol Metab. (2020) 64:205-22. doi: 10.20945/2359-3997000000255

35. Guillemot-Legris O, Masquelier J, Everard A, Cani PD, Alhouayek M, Muccioli GG. High-fat diet feeding differentially affects the development of inflammation in the central nervous system. J Neuroinflammation. (2016) 13:1-11. doi: 10.1186/s12974-016-0666-8

36. Libby AE, Bales E, Orlicky DJ, McManaman JL. Perilipin-2 deletion impairs hepatic lipid accumulation by interfering with sterol regulatory elementbinding protein (srebp) activation and altering the hepatic lipidome. J Biol Chem. (2016) 291:24231-46. doi: 10.1074/jbc.M116.759795

37. Kern PA, Di Gregorio G, Lu T, Rassouli N, Ranganathan G. Perilipin expression in human adipose tissue is elevated with obesity. J Clin Endocrinol Metab. (2004) 89:1352-8. doi: 10.1210/jc.2003-031388

38. Orlicky DJ, Libby AE, Bales ES, McMahan RH, Monks J, La Rosa FG, et al. Perilipin-2 promotes obesity and progressive fatty liver disease in mice through mechanistically distinct hepatocyte and extrahepatocyte actions. J Physiol. (2019) 597:1565-84. doi: 10.1113/JP2 77140

39. Xiong X, Bales ES, Ir D, Robertson CE, McManaman JL, Frank $\mathrm{DN}$, et al. Perilipin-2 modulates dietary fat-induced microbial global gene expression profiles in the mouse intestine. Microbiome. (2017) 5:117. doi: 10.1186/s40168-017-0327-x

40. Rollins CPE, Gallino D, Kong V, Ayranci G, Devenyi GA, Germann J, et al. Contributions of a high-fat diet to Alzheimer's disease-related decline: a longitudinal behavioural and structural neuroimaging study in mouse models. NeuroImage Clin. (2019) 21:101606. doi: 10.1016/j.nicl.2018.11.016

41. World Health Organization. Double-Duty Actions For Nutrition. Policy Brief. World Heal Organ (2017). p. 10. Available online at: https://apps.who.int/ iris/bitstream/handle/10665/255414/WHO-NMH-NHD-17.2-eng.pdf?ua=1 (accessed February 08, 2021).

42. Menon S, Peñalvo JL. Actions targeting the double burden of malnutrition: a scoping review. Nutrients. (2020) 12:1-14. doi: 10.3390/nu12010081

43. Pradeilles R, Baye K, Holdsworth M. Addressing malnutrition in low- and middle-income countries with double-duty actions. Proc Nutr Soc. (2019) 78:388-97. doi: 10.1017/S0029665118002616

44. Antunes MM, Godoy G, de Almeida-Souza CB, da Rocha BA, da Silva-Santi LG, Masi LN, et al. A high-carbohydrate diet induces greater inflammation thanahigh-fatdietinmouseskeletalmuscle. Brazilian J Med Biol Res. (2020) 53:4-11. doi: 10.1590/1414-431×20199039

Conflict of Interest: The authors declare that the research was conducted in the absence of any commercial or financial relationships that could be construed as a potential conflict of interest.

Copyright (c) 2021 Leocádio, Lopes, Dias, Alvarez-Leite, Guerrant, Malva and Oriá. This is an open-access article distributed under the terms of the Creative Commons Attribution License (CC BY). The use, distribution or reproduction in other forums is permitted, provided the original author(s) and the copyright owner(s) are credited and that the original publication in this journal is cited, in accordance with accepted academic practice. No use, distribution or reproduction is permitted which does not comply with these terms. 